\title{
Evaluation of bactericidal activity of Hannon honey on slowly growing bacteria in the chemostat
}

\author{
This article was published in the following Dove Press journal: \\ Drug, Healthcare and Patient Safety \\ 15 October 2014 \\ Number of times this article has been viewed
}

\author{
Najib Sufya' \\ Noora Matar \\ Rawanda Kaddura' \\ Abdulaziz Zorgani ${ }^{2}$ \\ 'Department of Microbiology and \\ Immunology, Faculty of Pharmacy, \\ ${ }^{2}$ Department of Microbiology and \\ Immunology, Faculty of Medicine, \\ University of Tripoli, Tripoli, Libya
}

Correspondence: Abdulaziz Zorgani Department of Microbiology and Immunology, Faculty of Medicine, University of Tripoli, PO Box 12456 Tripoli, Libya

Tel +2 I8 9| 37| 856।

Email zorgania@yahoo.com

\begin{abstract}
There is renewed interest in the therapeutic use of honey, including use in the treatment of infected wounds and burn patients. In this study, we have assessed the antibacterial activity of Libyan floral Hannon honey on Escherichia coli and Staphylococcus aureus, both known to infect wounds. The effects of four concentrations (5\%-30\%) of honey were compared with that of four antibiotics (ampicillin, tetracycline, polymyxin, and ciprofloxacin) on the growth of these bacteria at early $\log$, mid $\log$, and late log phases. It has been shown that E. coli and $S$. aureus are to some degree susceptible during mid log phase compared with late log phase, demonstrated by their complete resistance to antibiotics. Chemostat culture was used to investigate the effect of honey on E. coli grown at a steady state with specific growth rates between 0.1 to 0.5 hour $^{-1}$. The rate of killing was distinctively clear during the two stages of growth monitored: there was a relatively moderate reduction at the slow growth phase $\left(0.1\right.$ to 0.3 hour $\left.^{-1}\right)$, while a dramatic reduction was obtained at the fast growth phase $\left(0.3\right.$ to 0.5 hour $\left.^{-1}\right)$, reaching a complete reduction at 0.5 hour $^{-1}$. These results complement data using the cup-cut technique. The antibacterial effect of honey was concentration and time dependent, the bactericidal effect was indeed observed at low concentrations, it demonstrates that the honey has more impact on slow growing bacteria than antibiotics have. We suggest that more reduction could be achieved at higher concentrations of honey. These results may have important clinical implications, such as for the management of wound and burn patients.
\end{abstract}

Keywords: antibiotic, killing, Libya, Escherichia coli, Staphylococcus aureus

\section{Introduction}

Honey has been used for thousands of years as an empirical compound for the treatment of wounds and prevention of infection. Many studies have shown that honey strongly reduces bacterial colonization and accelerates wound healing compared with silver sulfadiazine treatment. ${ }^{1-3}$ The emergence of bacterial resistance to a wide range of antibiotics has led to a reevaluation of natural therapeutic agents including honey. ${ }^{4}$ Many studies have evaluated the therapeutic proprieties of manuka honey against a wide range of medically important bacteria. ${ }^{5-8}$ However, honey is produced from many floral sources, and its antimicrobial activity varies markedly with its origin and processing. ${ }^{9-11}$ This variation can be attributed to differences in the enzymatic action and in the presence of additional antimicrobial components, such as methylglyoxal derived from the floral sources. ${ }^{12-14}$ The antibacterial activity of honey is highly complex due to the involvement of multiple compounds and due to the large variation in the concentrations of these compounds in honey. ${ }^{15}$ 
Growth of Pseudomonas aeroginosa, S. aureus, and E. coli is known to be inhibited by honey. ${ }^{16-19}$ It has been known that stationary phase where bacteria are slow growing exhibit general resistance to a variety of antimicrobial agents. On the other hand, exponentially growing bacteria exhibit a significant susceptibility to deployed bacteria. In this study, we investigated the ability of the local honey (Hannon) to inactivate $S$. aureus and $E$. coli isolates at different growth rates ranging from exponential to late exponential-stationary phase where the growth rate at the latter approaches zero (dormant, quiescent) compared with a variety of antimicrobials.

\section{Materials and methods Honey}

The Hannon honey samples used in this study were obtained from commercial producers in Tripoli, Libya. Prior to assay, samples of honey were diluted with sterile phosphate buffer $(0.01 \mathrm{M})$ to give final concentrations of $(\mathrm{v} / \mathrm{v}) 5 \%(7 \mathrm{~g} / \mathrm{mL})$, 10\% (14 g/mL), 15\% (21 g/mL), 20\% (28 g/mL), 25\% (35 g/mL), and 30\% (42 g/mL) honey; diluted samples were frozen until use. ${ }^{20}$ Experiments used Hannon honey that was autoclaved before dilution as well as nonautoclaved honey. All procedures were carried out under aseptic conditions.

\section{Bacteria}

Two bacteria common to wound infections were used in the antimicrobial assays, E. coli (ATCC C600) and S. aureus (ATCC 6538). Antibiotic disks used throughout this study were ampicillin $10 \mu \mathrm{g}$, ciprofloxacin $5 \mu \mathrm{g}$, tetracycline $30 \mu \mathrm{g}$, and polymexin $300 \mu \mathrm{g}$ (Oxoid). Nutrient broth, nutrient agar, and Mueller Hinton broth and agar were used throughout the study (BDH, Poole, UK).

\section{Modes of bacterial growth}

\section{Batch culture}

Bacterial growth was maintained at both early and mid log exponential phases followed by late exponential phase. This was achieved by establishing the growth curve for both control organisms under fixed conditions. This was determined by observation of absorbance of aliquots from the bacterial cultures at $470 \mathrm{~nm}$ (1 cm path). Absorbance was measured using a spectrophotometer (PU 8675 Vis spectrophotometer; Philips). The late exponential phase, prior to entry into the stationary phase, was determined to be at $\mathrm{A}_{470 \mathrm{~nm}} 1.2$.

\section{Continuous culture}

Continuous culture using chemically defined medium was performed to extrapolate the effect of various antibiotics compared with that of Hannon honey on the E. coli isolate. This was conducted deploying small scale $(60 \mathrm{~mL})$ all glass chemostats using a simple salt medium with glycerol as the sole carbon source. ${ }^{21,22}$ Specific growth rates (from the fastest to the slowest) were achieved between 0.1 and 0.5 hour $^{-1}$ at a steady state of at least seven volume changes as described by Gilbert and Brown. ${ }^{23}$ Specifically, 0.1 hour $^{-1}$ was the target dilution rate to evaluate the ability of honey to inactivate slow growing (dormant) populations of E. coli.

\section{Antimicrobial susceptibility experiments}

Antimicrobial susceptibility experiments for honey were performed by starting with specific $\mathrm{cfu} \cdot \mathrm{mL}^{-1}$. This was conducted by transferring $5 \mathrm{~mL}$ of the exponential and late exponentialstationary phase broth cultures (optical density $470 \mathrm{~nm}, \mathrm{~A} 0.9$, and 1.2, respectively) for both $E$. coli and $S$. aureus strains, or from the chemostat culture of $E$. coli at specific dilution rate to $15 \mathrm{~mL}$ sterile $0.9 \% \mathrm{w} / \mathrm{v}$ normal saline to place the bacteria at a concentration of $1 \times 10^{8} \mathrm{cfu} \cdot \mathrm{mL}^{-1}$. A $1 \mathrm{~mL}$ sample was taken at 15 minute intervals up to 5 hours and then at 24 hours, where the serial dilutions were performed and the viable count calculated using the spread plate technique. Viable culture counts were performed by transferring $100 \mu \mathrm{L}$ of each sample taken onto predried nutrient agar plates and then incubated for 24 hours prior to colony counting. Results were expressed as the log of survivors and the percentage log of survivors for Hannon honey against exposure time. These processes were used to set up the survival curve (dose-response curve). The Hannon honey dilution series was added to tubes with known number of bacteria ( $\mathrm{cfu} \cdot \mathrm{mL}^{-1}$ ) and incubated overnight. The number of bacteria were then estimated in each test tube using the spread plate technique where the bacterial colony found on each plate is a function of the antimicrobial activity of the honey. All experiments were repeated twice, and the mean was used in our experiments. A control was performed for each experiment alongside the test samples. Antibiotic susceptibility tests were performed according to Kirby-Bauer Disc Diffusion method, and the antibiotic susceptibility/resistances were determined according to Clinical and Laboratory Standards Institute. ${ }^{24}$ In the case of honey, the cup-cut agar method was also performed, and data were compared and extrapolated.

\section{Results}

The effect of the four antibiotics tested on E. coli and S. aureus clearly varied depending on growth phase (Table 1). For E. coli, polymixin, tetracycline, and ciprofloxacin affected early log phase growth. During the mid log phase, an increased killing efficiency was demonstrated by polymixin and ciprofloxacin, 
Table I The effect of a variety of antibiotics on bacterial growth at three different phases of Escherichia coli and Staphylococcus aureus

\begin{tabular}{|c|c|c|c|}
\hline \multirow[t]{2}{*}{$\begin{array}{l}\text { Growth } \\
\text { phases }\end{array}$} & \multirow[t]{2}{*}{ Type of antibiotic } & \multicolumn{2}{|c|}{$\begin{array}{l}\text { Zone of } \\
\text { inhibition } / \mathrm{mm}\end{array}$} \\
\hline & & E. coli & S. aureus \\
\hline \multirow[t]{4}{*}{ Early log phase } & Ampicillin $10 \mu \mathrm{g}$ & 6 & 6 \\
\hline & Polymexin $300 \mu g$ & 10 & 6 \\
\hline & Tetracycline $30 \mu \mathrm{g}$ & 20 & 6 \\
\hline & Ciprofloxacin $5 \mu \mathrm{g}$ & 31 & 28 \\
\hline \multirow[t]{4}{*}{ Mid log phase } & Ampicillin $10 \mu \mathrm{g}$ & 6 & 6 \\
\hline & Polymexin $300 \mu \mathrm{g}$ & 14 & 6 \\
\hline & Tetracycline $30 \mu \mathrm{g}$ & 17 & 6 \\
\hline & Ciprofloxacin $5 \mu \mathrm{g}$ & 34 & 31 \\
\hline \multirow[t]{4}{*}{ Late log phase } & Ampicillin $10 \mu \mathrm{g}$ & 6 & 6 \\
\hline & Polymexin $300 \mu \mathrm{g}$ & 6 & 6 \\
\hline & Tetracycline $30 \mu \mathrm{g}$ & 6 & 6 \\
\hline & Ciprofloxacin $5 \mu \mathrm{g}$ & 6 & 6 \\
\hline
\end{tabular}

$14 \mathrm{~mm}(40 \%)$ and $34 \mathrm{~mm}(34 \%)$ respectively. However, ampicillin showed no activity during early and mid log phases. Late $\log$ phase populations were resistant to all antibiotics. Meanwhile, $S$. aureus resistance was more evident during all growth phases compared with $E$. coli. This was clearly obvious against all antibiotics examined, with the exception of ciprofloxacin as follows: $28 \mathrm{~mm}$ zone of inhibition observed at early log phase, while during mid log phase, it showed an enhanced activity by about $14 \%$ but no activity at late $\log$ phase.

Table 2 shows the antibacterial activity of Hannon honey on E. coli cultures in mid $\log$ and late $\log$ phases of growth. Sustained antibacterial activity on mid log phase was clearly displayed between the control and the test. At concentrations of $5 \%-25 \% \mathrm{v} / \mathrm{v}$ of the nonautoclaved honey, viable counts dramatically decreased from 41 to 2 colonies (95.1\%). Further reduction of the population $(97.6 \%$ ) was obtained at $30 \% \mathrm{v} / \mathrm{v}$. In the case of late $\log$ phase populations, Hannon honey showed evidence of antibacterial action. Although no killing of the

Table 2 The effect of nonautoclaved honey on mid log and late log phase growth of Escherichia coli

\begin{tabular}{|c|c|c|c|c|}
\hline \multirow{3}{*}{$\begin{array}{l}\text { Concentration } \\
\text { of honey (\%) }\end{array}$} & \multicolumn{4}{|c|}{ Number of colonies } \\
\hline & \multicolumn{2}{|c|}{ Mid log phase } & \multicolumn{2}{|c|}{ Late log phase } \\
\hline & \multicolumn{2}{|c|}{$\begin{array}{l}\text { Nonautoclaved } \\
\text { Number of colonies \% }\end{array}$} & \multicolumn{2}{|c|}{$\begin{array}{l}\text { Nonautoclaved } \\
\text { Number of colonies \% }\end{array}$} \\
\hline 5 & 2 & 95.1 & 300 & 0 \\
\hline 10 & 2 & 95.1 & 187 & 37.7 \\
\hline 15 & 2 & 95.1 & 120 & 60 \\
\hline 20 & 2 & 95.1 & 120 & 60 \\
\hline 25 & 2 & 95.1 & 84 & 72 \\
\hline 30 & 1 & 97.6 & 84 & 72 \\
\hline Control $10^{-4}$ & 41 & & 300 & \\
\hline
\end{tabular}

population was exhibited at $5 \%$ where the number of colonies after exposure remained $300 \mathrm{cfu} \cdot \mathrm{mL}^{-1}$, a $72 \%$ reduction was achieved at $30 \%$ concentration of honey. The autoclaved honey samples showed similar results, with an increased magnitude of activity at $30 \%$ concentration of honey (data not shown). All bacterial numbers were noticed after 1 hour sampling time were further sampling time plates did not show any colony. Similar effects were noticed against $S$. aureus (data not shown).

Continuous culture results were derived from performing chemostat experiments of E. coli populations grown at a steady state with specific growth rates between 0.1 to 0.5 hour $^{-1}$. E. coli was exposed to Hannon honey at concentrations of $5 \%, 15 \%$, and $30 \%(\mathrm{v} / \mathrm{v})$. The effect of the honey was observed during all growth rates of E. coli (Figure 1). There was a relatively moderate reduction at the slow growth phase ( 0.1 to 0.3 hour $\left.^{-1}\right)$ but a dramatic reduction at the fast growth phase ( 0.3 to 0.5 hour $\left.^{-1}\right)$. The percentage of log survival reached a complete (zero survival) reduction at 0.5 hour $^{-1}$ when exposed to honey at a concentration of $30 \%$.

\section{Discussion}

Emerging evidence from clinical studies suggests that honey is at least as effective as conventional antimicrobial therapy in healing wounds, particularly in very refractory cases, such as in individuals with diabetes, the elderly, and extensively burned patients, ${ }^{25,26}$ but further clinical studies are necessary for robust statistical appraisal. ${ }^{27}$ To date, more than 80 different microbial species associated with wound infections have been shown to

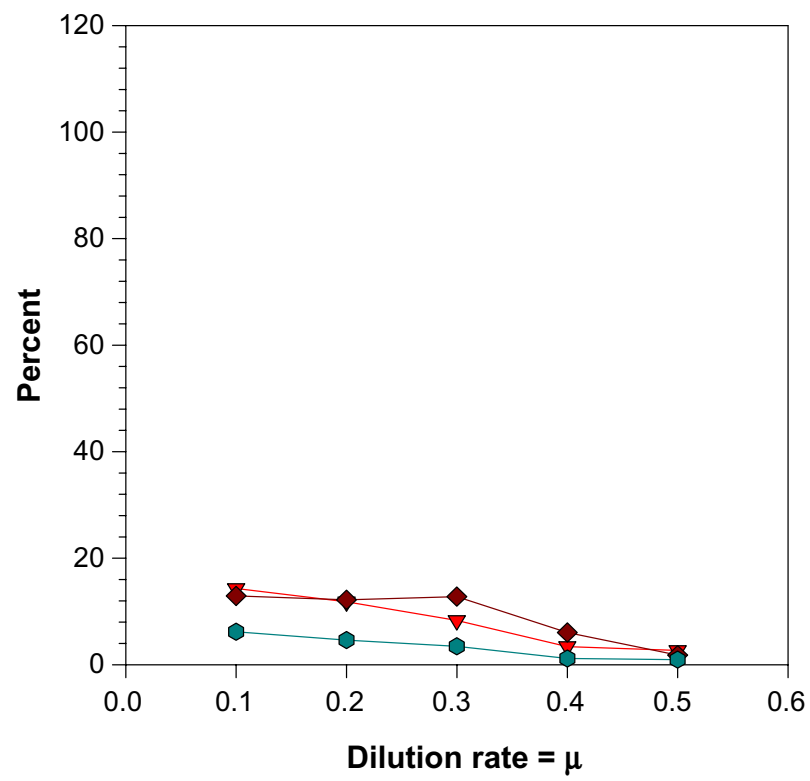

Figure I The effect of various concentrations ( $v / v)$ of honey on Escherichia coli populations at various growth rates.

Note: $\$$, $5 \%$ concentration; $\mathbf{\nabla}, 15 \%$ concentration; $30 \%$ concentration. 
be inhibited by honey. ${ }^{28-31}$ The failure of antibiotic treatments to eliminate certain bacterial infections has become both more evident and better understood in the past several decades. In the current study, the use of low concentrations of natural honey had a high potency antibacterial activity especially for slow growing bacteria compared with antibiotics, which would be generally useful in a clinical situations.

The susceptibility of $E$. coli and $S$. aureus has been investigated compared with four types of antibiotics at three different stages of bacterial growth. The influence of growth phase on the resistance of these bacteria was exhibited at late stage of bacterial growth phase. It has been shown that $E$. coli and S. aureus are to some degree susceptible during mid log phase compared with late log phase. This was obvious against all antibiotics tested. The efficacy of ciprofloxacin was evident for both bacteria during early and mid log phases but declined during late log phase. On the other hand, ampicillin showed no activity at any stage. $S$. aureus resistance was clearly demonstrated during all growth phases compared with E. coli. However, during late log phase for both types of bacteria was equally demonstrated their complete resistance to antibiotics. These results correlate with early investigations that early and mid $\log$ phases are less resistant compared with late log phase cells. ${ }^{32,33}$

Hannon honey, whether autoclaved or nonautoclaved, showed a sustained level of antibacterial activity during mid log phase. This was clearly displayed in the difference in bacterial count between the control and the test. At 5\% v/v of the nonautoclaved honey, the number of bacteria was dramatically decreased $(95.1 \%)$ from 41 colonies to 2 colonies. Further reduction of the population $(97.6 \%$ ) was obtained at $30 \% \mathrm{v} / \mathrm{v}$, which was consistent with previous reports that found therapeutic manuka honey was $3.7 \%$ for $E$. coli and $5.8 \%-10.8 \%$ for P. aeroginosa. Similar results were shown to exhibit antibacterial activity following treatment with other honey types. ${ }^{10,11,34}$ Hannon honey has shown less antibacterial action during late $\log$ phase. Although no killing of the population was exhibited at $5 \%$ of honey, but it retained superior continuous bactericidal activity from $36.8 \%$ and reached $72 \%$ of bacterial population at the $30 \%$ concentration of honey. The autoclaved honey samples showed similar results, with an increased magnitude of activity from $10 \%$ to $30 \%$ concentration of honey (data not shown). A similar effect was noticed against $S$. aureus (data not shown).

These results emphasize previous studies that showed that slowly growing bacteria (late log phase) are less susceptible to antibiotic action than those grown at optimum rates. ${ }^{35,36}$ This might be partially explained by phenotypic characteristic differences. ${ }^{37-39}$ In this study, no antibiotics had any effect on E. coli and S. aureus during late log phase compared to honey, a $72 \%$ reduction at the $30 \%$ concentration demonstrates that honey has a superior action on slow growing bacteria than antibiotics, and we suggest that more reduction could be achieved at a higher concentration of honey.

Chemostat is the only currently available method that allows bacterial growth rates to be controlled over a wide range under otherwise constant conditions. Chemostat cultures are therefore an invaluable tool in efforts to study the effects of reduced growth rates characteristic of bacteria growing in vivo. We have used chemostat cultures to investigate the effect of honey on bacterial growth rate on honey activity. The results presented herein show that the bactericidal activity of honey was exhibited on E. coli populations and grown at a steady state with specific growth rates between 0.1 to 0.5 hour $^{-1}$. E. coli was exposed to Hannon honey at concentrations of $5 \%, 15 \%$, and $30 \%(\mathrm{v} / \mathrm{v})$. The rate of killing was distinctively clear during the two stages of growth rate; there was a relatively moderate reduction at the slow growth phase $\left(0.1\right.$ to 0.3 hour $\left.^{-1}\right)$, then there was dramatic reduction at the fast growth phase ( 0.3 to 0.5 hour $\left.^{-1}\right)$, the percentage of log survival reached a complete (zero survival) reduction at 0.5 hour $^{-1}$ when exposed to honey at a concentration of $30 \%$. These results complement the above data using the cup-cut technique.

Given the difficulty in treating infected chronic wounds due to multiresistant bacteria, honey is increasingly being used as a topical treatment for these wounds. There are several reports of its successful application in the treatment of chronic wound infections not responding to antibiotic therapy. ${ }^{40}$ In addition, honey could effectively complement standard antibiotics, especially in general wounds and in burn wound infections caused by E. coli, Staphylococci, Pseudomonas, and Streptococci. ${ }^{41-44}$

\section{Conclusion}

In contrast to antibiotics, the antibacterial effect of Hannon honey was concentration and time dependent, the bactericidal effect was indeed observed at low concentration. The high antibacterial activity exerted by Hannon honey, and the possible benefits in clinical implications of bacterial infections, warrant further investigation.

\section{Acknowledgment}

The authors would like to thank Dr John Klena for his special contributions. 


\section{Disclosure}

The authors declare no conflicts of interest in this work.

\section{References}

1. Moore OA, Smith LA, Campbell F, Seers K, McQuay HJ, Moore RA. Systematic review of the use of honey as a wound dressing. BMC Complement Altern Med. 2001;1:2.

2. Jull AB, Rodgers A, Walker N. Honey as a topical treatment for wounds. Cochrane Database Syst Rev. 2013;2:CD005083.

3. Voidarou C, Alexopoulos A, Plessas S, et al. Antibacterial activity of different honeys against pathogenic bacteria. Anaerobe. 2011;17(6):375-379.

4. Johnson DW, van Eps C, Mudge DW, et al. Randomized, controlled trial of topical exit-site application of honey (Medihoney) versus mupirocin for the prevention of catheter-associated infections in hemodialysis patients. J Am Soc Nephrol. 2005;16(5):1456-1462.

5. Lusby PE, Coombes AL, Wilkinson JM. Bactericidal activity of different honeys against pathogenic bacteria. Arch Med Res. 2005;36(9):464-467.

6. Lin SM, Molan PC, Cursons RT. The controlled in vitro susceptibility of gastrointestinal pathogens to the antibacterial effect of manuka honey. Eur J Clin Microbiol Infect Dis. 2011;30(4):569-574.

7. Lu J, Turnbull L, Burke CM, et al. Manuka-type honeys can eradicate biofilms produced by Staphylococcus aureus strains with different biofilm-forming abilities. PeerJ. 2014;25:(2):e326.

8. Packer JM, Irish J, Herbert BR, et al. Specific non-peroxide antibacterial effect of manuka honey on the Staphylococcus aureus proteome. Int $J$ Antimicrob Agents. 2012;14(1):43-50.

9. Cooper RA, Hales E, Molan PC. The efficacy of honey in inhibiting of stains of Pseudomonas aeroginosa from infected burns wound. J Burn Care Rehabil. 2002;23(6):366-370.

10. Cooper RA, Molan PC. The use of honey as an antiseptic in managing Pseudomonas infection. J Wound Care. 1999;8(4):161-164.

11. Willix DJ, Molan PC, Harfoot CG. A comparison of the sensitivity of wound-infecting species of bacteria to the antibacterial activity of manuka honey and other honey. J Appl Bacteriol. 1992;73(5):388-394.

12. Irish J, Blair S, Carter DA. The antibacterial activity of honey derived from Australian flora. PLoS One. 2011;6(3):e18229.

13. Kwakman PH, Van den Akker JP, Guclu A, et al. Medical-grade honey kills antibiotic-resistant bacteria in vitro and eradicates skin colonization. Clin Infect Dis. 2008;46(11):1677-1682.

14. Boekema BK, Pool L, Ulrich MM. The effect of a honey based gel and silver sulphadiazine on bacterial infections of in vitro burn wounds. Burns. 2013;39(4):754-759.

15. Kwakman PHS, Zaat SA. Antibacterial components of honey. IUBMB Life. 2012;64(1):48-55.

16. Obi C, Ugji E, Edun SA, Lawal SF, Anyiwo CE. The antibacterial effect of honey on diarrhoea-causing bacterial agents isolated in Lagos, Nigeria. Afr J Med Sci. 1994;23(3):257-260.

17. Al-waili N, Al-Ghamidi A, Ansari MJ, A-lattal Y, Salom K. Synergistic effects of honey and propolis toward drug multi-resistant Staphylococcus aureus, Escherichia coli and Candida albicans isolates in single and polymicrobial cultures. Int J mred Sci. 2012;9(9):793-800.

18. Kwakman PHS, Velde AA, de Boer L, Vandenbroucke-Grauis CM, Zaat SA. Two major medicinal honeys have different mechanisms of bactericidal activity. PloS One. 2011;6(3):e17709.

19. Kwakman P, Van den Akker J, Guclu A, et al. Medical-grade honey kills antibiotic-resistant bacteria in vitro and eradicates skin colonization. Clin Infect Dis. 2008;46(11):1677-1682.

20. Mulu A, Tessema B, Derbie F. In vitro assessment of the antimicrobial potential of honey on common human pathogens. Ethiop J Health Dev. 2004;18(2):107-111.

21. Gilbert P, Stuart A. Small-scale chemostat for the growth of mesophilic and themophilic microorganisms. Laboratory Practice. 1977;26(8):627-628.
22. Brown MRW, Gilbert P, editors. Microbiological Quality Assurance: A Guide Towards Relevance And Reproducibility Of Inocula. Boca Raton, FL: CRC Press; 1995.

23. Gilbert $P$, Brown MR. Influence of growth rate and nutrient limitation on the gross cellular composition of Pseudomonas aeruginosa and its resistance to 3- and 4-chlorophenol. J Bacteriol. 1978;133(3):1066-1072.

24. Clinical and Laboratory Standards Institute. Methods for Dilution Antimicrobial Susceptibility Tests for Bacteria That Grow Aerobically. 9th ed. Wayne, PA: Clinical and Laboratory Standards Institute; 2012. CLSI publication M7-A9.

25. Kegels F. Clinical evaluation of honey-based products for lower extremity wounds in a home care settings. Wounds UK. 2011;7(2):46-53.

26. Smaropoulos E, Romeos S, Dimitriadou C. Honey-based therapy for paediatric burns and dermal trauma compared to standard hospital protocol. Wounds UK. 2011;7(2):33-40.

27. Lee DS, Sinno S, Khachemoune A. Honey and wound healing: an overview. Am J Clin Derm. 2011;12(3):181-190.

28. Irish J, Carter DA, Shokohi T, Blair SE. Honey has an antifungal effect against Candida species. Med Mycol. 2006;44(3):289-291.

29. Molan PC. The antibacterial activity of honey. Variation in the potency of the antibacterial activity. Bee World. 1992;73(1):59-76.

30. Blair SE, Carter DA. The potential for honey in the management of wounds and infection. Healthcare Infect. 2005;10(1):24-31.

31. Blair SE, Cokcetin NN, Harry EJ, Carter DA. The unusual antibacterial activity of medical-grade leptosermum honey: antibacterial spectrum, resistance and transcriptome analysis. Eur J Clin Microbial Infect Dis. 2009;28(10):1199-1208.

32. Cozens RM, Tuomanen E, Tosch W, Zak O, Suter J, Tomasz A. Evaluation of the bactericidal activity of $\beta$-lactam antibiotics on the slowly growing bacteria cultured in the chemostat. Antimicrob Agents Chemoth. 1986;29(5):797-802.

33. Tuomanen E, Cozens R, Tosch W, Zako O, Tomasz A. The rate of killing of Escherichia coli by $\beta$-lactam antibiotics is strictly proportional to the rate of bacterial growth. J Gen Microb. 1986;132(5): 1297-1304.

34. Wilkinson JM, Cavanagh HM. Antibacterial activity of 13 honeys against Escherichia coli and Pseudomonas aeruginosa. J Med Food. 2005;8(1):100-103.

35. Sufya N, Gilbert P. Resistance, persistence and recalcitrance of bacterial biofilms: a state "Tail" of lassitude. Tripolitana M J. 2010;1: $1-10$.

36. Sufya N, Ghnan N, Mohamed S, Ermeli N. Antimicrobial activity of Ramath (Retama raetem) extract against Gram positive and Gram negative bacteria. World Academy Science, Eng Technol. 2013;75: 331-337.

37. Balaban NQ, Merrin J, Chait R, Kowlik L, Leibler S. Bacterial resistance as a phenotypic switch. Science. 2004;305(5690):1622-1625.

38. Sufya N, Gilbert P. Bacterial biofilms: will develop a focal point for the evolution of antibacterial resistance. $L J$ Medical Res. 2010;7:5-15.

39. Sufya N, Allison DG, Gilbert P. Clonal variation in maximum specific growth rate and susceptibility towards antimicrobials. J Appl Microb. 2003;95(6):1261-1267.

40. Efem S. Clinical observations on the wound healing properties of honey. Brit J Surg. 1988;75(7):679-681.

41. Adeleke OE, Olaitan PB. The antipseudomonal property of honey and gentamycin. Ann Burns Fire Disasters. 2006;19(3):140-143.

42. Boekema BK, Pool L, Ulrich MM. The effect of a honey based silver sulphadiazine on bacterial infections of in vitro burn wounds. Burns. 2013;39:754-759.

43. Shenoy VP, Ballal M, Shivananda P, Bairy I. Honey as an antimicrobial agent against Pseudomonas aeroginosa isolated from wounds. $J$ Glob Infect Dis 2012;4(2):102-105.

44. Maddocks SE, Lopez MS, Rowlands RS, Cooper RA. Maunka honey inhibits the development of Streptococcus pyogenes biofilms and causes reduced expression of two fibronectin binding proteins. Microbiology 2012;158(3);781790. 
Drug, Healthcare and Patient Safety

Dovepress

\section{Publish your work in this journal}

Drug, Healthcare and Patient Safety is an international, peer-reviewed open-access journal exploring patient safety issues in the healthcare continuum from diagnostic and screening interventions through to treatment, drug therapy and surgery. The journal is characterized by the rapid reporting of reviews, original research, clinical, epidemiological and

post-marketing surveillance studies, risk management, health literacy and educational programs across all areas of healthcare delivery. The manuscript management system is completely online and includes a very quick and fair peer-review system. Visit http://www.dovepress.com/ testimonials.php to read real quotes from published authors.

Submit your manuscript here: http://www.dovepress.com/drug-healthcare-and-patient-safety-journal 